\title{
Psychodiagnostics of Preschool children with Autism
}

\section{Psicodiagnóstico de Preescolares con Autismo}

\author{
Nabiyeva Aida Subhan \\ Department of Psychology and Special Education of ARTI, Psychologist of the Center for Modern Psychology, \\ Azerbaijan.
}

ORCID: https://orcid.org/0000-0002-0870-0226

Recibido 30-01-20 Revisado 20-04-20 Aprobado 10-05-20 En línea 15-05-20

*Correspondencia

E-mail: namazovaaida@mail.ru

\section{Citar como:}

Nabiyeva, A. (2020). Psychodiagnostics of Preschool children with Autism. Propósitos y Representaciones, Doi: http://dx.doi.org/10.20511/pyr2020.v8n3.540

(C) Universidad San Ignacio de Loyola, Vicerrectorado de Investigación, 2020. $\mathrm{nd} / 4.0 /)$. 


\section{Summary}

The article deals with the training and psycho-correction of children with autism. Psychological correction preventing the development of autism plays an important role nowadays. Significant experience has already been gained through clinical and psychiatric studies in this area. Diagnostic criteria for this problem were first identified by Kanner. The article explores the possibilities of determining the characteristics and level of development of purposeful formation of communication skills in preschool children with autism. Based on the obtained indicators, methods that will help to identify and implement more effective methods of pedagogical correction with children with autism individually and in groups are studied as well.

Key words: World Health Organization; Autism; Psychological Correction; Diagnosis, Theraphy,

\section{Resumen}

El artículo trata sobre el entrenamiento y la psico-corrección de niños con autismo. La corrección psicológica que previene el desarrollo del autismo juega un papel importante hoy en día. Ya se ha obtenido una experiencia significativa a través de estudios clínicos y psiquiátricos en esta área. Kanner identificó por primera vez los criterios de diagnóstico para este problema. El artículo explora las posibilidades de determinar las características y el nivel de desarrollo de la formación intencional de habilidades de comunicación en niños en edad preescolar con autismo. Con base en los indicadores obtenidos, también se estudian métodos que ayudarán a identificar e implementar métodos más efectivos de corrección pedagógica con niños con autismo individualmente y en grupos.

Palabras clave: Organización Mundial de la Salud; Autismo, Corrección psicológica, Diagnóstico; Terapia.

\section{Introducción}

Although the concept of "autism" includes a wide range of noticeable situations, in all cases it is characterized by the following features. ASD is disorder of psychological development. This is a special type of developmental disorder that occurs in a child due to a biological deficiency. This provides a basis for the diagnosis of "Autism" (Kınac1, 2013).

According to experts, autism is the fourth most common chronic neurological and mental disorder in children after mental retardation, epilepsy and cerebral palsy (American Psychiatric Association, 2008). Early diagnosis of children with autism, as noted, is one of the most important conditions.

Diagnostic criteria for this problem were first identified by Kanner. Although these criteria are classical (empirical), they have not lost their relevance. Because L. Kanner has studied this problem for a long time and extensively, the symptoms he identifies, while maintaining its scientific and practical significance, help to recognize children with autism even when seen from afar. The diagnostic signs of autism are as follows (Kınac1, 2013).

When talking about their children, many parents say with great regret that their children spend most of their time playing alone. As if they really have their own world, and they live in their own world and don't want to be disturbed. Normally, when a child is 9-10 months old, he can say 3-5 words like mother, father, grandfather. The most important factor in children with 
autism is not starting to speak on time. Most of these children do not even use a word until they are 2-3 or sometimes 4 years old. In some cases, though a child with autism show some symptoms, but his speech becomes active. Although he actively uses words until the age of 3, after this age his speech may be completely blocked. But how can autism be diagnosed?For this, it is necessary to refer to various diagnostic criteria developed by specialists.

The most widely used criteria in this regard are defined by the World Health Organization and are included in ICD 10 (tenth edition of the International Classification of Diseases) (ICD-10 (WHO, 1987), as well as in DSM( fourth edition of diagnostic statistical manual) published by the American Psychiatric Association (APA, 1994).

\section{Cyberbullying (Ciberacoso)}

For clarifying the levels of explanation for developmental disorders of autism, it is necessary to refer to the scheme proposed by F. Appe (Appe, 2005) and U. Frit (Frith, 1979). This scheme consists of three explanation levels and describes the relationship of cause-and-effect models among these levels.

Part (a) of the scheme shows the cases of disruption caused by biological causes $(\mathrm{O})$, which can lead to different results at the behavioral and cognitive levels (S1 - S2; C1 - C2), respectively. In part (b) there is a disorder that has different biological causes (O1 and $\mathrm{O} 2)$, which leads to different manifestations of behavior (S1 and S2), but only one cognitive (C) defect. And part (c) shows a disorder characterized by behavioral manifestations ( $\mathrm{S})$ with multiple biological causes (O1 and $\mathrm{O} 2)$ and cognitive dysfunctions ( $\mathrm{C} 1$ and $\mathrm{C} 2)$. F. Appe also notes that when specifically explaining the causes of autism, it is important not only to distinguish between different levels of description, but also to consider it over different (specifically, three) time scales. The following are suggested as such scales:

1) The first time scale is the scale of evolution as a whole. The effect of natural selection is considered by taking the gene as a unit of analysis within the time scale;

2) The second time scale - is the scale of individual development. In this case, the focus is on the individual (or his or her biological, behavioral, and cognitive mechanisms);

3) Finally, there are sufficiently short intervals at which any mechanism of the process works.

It should be noted that the last two time scales are of particular importance when considering autism.

According to the DSM-5, the criteria required for the diagnosis of Autism Spectrum Disorder are, as noted below, the presence of a weakness in social relationships, which is manifested in different forms, first and foremost, now or in the past:

1) Difficulties in reacting during social-emotional relations;

2) Difficulties in non-verbal attitudes and behaviors used for social relations (for example: abnormal eye contact, difficulty in understanding body language or gestures, facial expressions and deficiencies in body language);

3) difficulty in developing, maintaining and understanding relationships, inappropriate behavior in different environments, inability to form imaginary games, inability to make friends, lack of interest in coevals and other children.

The degree of autism is assessed by difficulty in social skills and limited, repetitive behaviors. Repetitive behaviors, interests, or actions that are present or limited in the past, manifested in the presence of at least two of the following: - repetitive motor actions, use of objects or in speaking (simple motor stereotypes, arranging or spinning toys, exolalia, idiocentric sentences ); - determination to be the same, ritualized verbal or non-verbal behaviors (high stress 
against small changes, harsh thinking, greeting rituals, intention to going the same way every day or having the same food); - subjectively abnormal, limited, fixed interests (excessive attachment to things that are not widely used, repetitive or limited interests); - emotionally excessive or very low sensitivity or excessive interest in the emotional aspects of the environment (indifference against hot and cold, unexpected reaction to certain sounds or touches, sniffing or excessive touching of objects, hypersensitivity to light or movements).

A) Symptoms should be present in the early stages of development.

B) Symptoms should cause problems in social and other fields. This disorder is called mental retardation or general developmental retardation. However, in some cases, mental retardation and Autism Spectrum Disorder are taken together. To diagnose Autism Spectrum Disorder and mental retardation, the overall development of social skills must be weak (DSM-5, 2013).

Table 1.

The main content of questions over $A$ and $B$ sections

\begin{tabular}{|c|c|}
\hline Variants & Content of questions \\
\hline$A-5$ & $\begin{array}{l}\text { Does your child play symbolic games (such as putting his/ her doll to sleep while } \\
\text { playing with it / driving a toy car from one place to another)? }\end{array}$ \\
\hline A -7 & Does your child use the index finger to show his interest in something? \\
\hline $\mathrm{B}-2$ & $\begin{array}{l}\text { Draw the child's attention, then point to an interesting object in the other corner of } \\
\text { the room and say, "Look! There is a ... (name the toy).". Look at the child's face. } \\
\text { Does the child look to the other side of the room to see the object you are pointing } \\
\text { to? }\end{array}$ \\
\hline$B-3$ & $\begin{array}{l}\text { Get the child's attention, give him a toy car / doll and ask, "Are you going to drive } \\
\text { the car / put the doll to bed?" . Does the child perform symbolic actions, such as } \\
\text { driving a car / putting the doll to bed? }\end{array}$ \\
\hline$B-4$ & $\begin{array}{l}\text { Ask the child, "Where is the light?" or say, "Show me the light." Does the child } \\
\text { point to the light with his index finger? }\end{array}$ \\
\hline
\end{tabular}

DSM suggests the following definition of autism:

I. Qualitative violation in social interaction, represented by two indicators:

a) significant violations in the use of non-verbal forms of behavior for the purpose of regulating social interaction;

b) inability to develop relationship with their covel;

c) inability to feel joy in other people's happiness;

d) lack of social and emotional interaction.

II. Qualitative violation of communication, at least, represented by any of the following indicators:

a) stagnation in speech delay or complete retardation of speech;

b) significant impairment of the ability of people with adequate speech to initiate or support any conversation with others;

c) stereotyped or repeated use of language, idiosyncratic speech;

d) lack of colorful, spontaneous (chaotic) games or social imitation games appropriate to the level of development; 
III. Limited, repetitive, and stereotypical forms of behavior, interests, and activities, represented by at least one of the following:

a) active activity on several limited and stereotyped types violated for intensity or direction;

b) obvious stubbornness to typical, non-functional rituals, rules;

c) stereotypical or repetitive mechanical movements (waving, turning, unusual body movements of fingers or hands);

d) play with parts of objects. of three:

IV. delay or disrupted activity in at least one of the following areas, starting before the age

(1) social interaction; speech used in social development;

(2) speech in communication;

(3) a symbolic or creative game.

Studies show that all people with autism suffer from three deficit areas called the "Laura Wing Triad" (L. Wing). The diagnosis of autism in modern practice, based on the application of both modern diagnostic schemes, is based on the assessment of the leading disorders covered by the "Laura Wing triad" :

- qualitative deterioration in the field of social interaction;

- qualitative deterioration in the field of verbal and non-verbal communication and imagination;

- limited repertoire of activities and interests. (Wing, 1981).

\section{Method}

\section{Population}

We started diagnostic research on the base of the the methods mentioned above. The research on the CHAT test was conducted mainly at the Psychological Center (Modern Psychology Center) in Baku. In the first part of the study, our goal was to determine the number of children suffering from autism among those who came to the center. The CHAT test, which is used in a number of countries around the world, is used for this purpose. We have conducted a CHAT test among 214 children attending classes at the psychological center since its inception. These children were mainly in the age group of 3-6 years( 3-4 years - 87 children, 4-5 years - 73 children, 5-6 years 54 children).

\section{Results}

The parents took part in the test with great interest. So, they noted that their children have rarely been tested with the participation of their parents. The test lasted for 9 months of 2016. Part A of the test is very easy to answer, while Part B, which is a practical part, is a bit difficult and requires responsibility. Completing Part B requires a completely free relationship and flexibility between the child and the developmental specialist. Let me note that the most favourite part of the children during the whole test was the cube construction. Talking to the parents who took part in the test, it became clear that they were able to get to know their children better. Most of them noted that they were worried about the questions dealing with autism whether their children suffer of it or not. There were those who thanked for the end of such worries (Table 2) 
Table 2.

Distribution of tested people

\begin{tabular}{lllll}
\hline \multicolumn{2}{c}{ Groups } & Characteristics of group & $\begin{array}{l}\text { by } \\
\text { number }\end{array}$ & $\begin{array}{l}\text { With } \\
\text { \% }\end{array}$ \\
\hline 1. Athigh risk of autism & $\begin{array}{c}\text { Answer "no" to A-5, A-7, B-2, B-3, B-4 } \\
\text { questions }\end{array}$ & 115 & 53,7 \\
2. At low risk of autism & $\begin{array}{c}\text { Answer "no" to A-7, B-4 questions } \\
\text { 3. With no risk of autism } \\
\text { Answer "yes" to A-5, A-7, B-2, B-3, B-4 }\end{array}$ & 45 & 21 \\
& $\begin{array}{c}\text { questions } \\
\text { The number of children participated in test }\end{array}$ & 214 & 100 \\
\hline
\end{tabular}

These children are the children of the parents who answered "no" to questions A5, A7 in PART A and B2, B3, B4 in PART B. The questions in these sections are based on active autistic symptoms. Let's focus on the questions in Part A:

Does your child play symbolic games (such as putting his/ her doll to sleep while playing with a doll / driving a toy car from one place to another)? Yes / No.

In Part B, the parents whose children suffer from autism answered "no" to the question 5. Because, as mentioned before, children with autism are not interested in toys, and can not play some games at an early age. It should be noted that children with autism can not even play imaginary games. This section warns us that the child has another symptom of autism.

Some parents whose children have successfully recovered from autism expressed their thoughts in handwriting: "The child learned this skill after coming to the center".

Does your child use the index finger to indicate interest in something? Yes / No.

This question is one of the questions asked by neurologists and psychiatrists when diagnosing autism. The ability of pointing a finger at an object of interest is generally not observed in children with autism. These kind of children touch the objects of interest with their parents or relatives' hands and show that they want something like that.

As I mentioned above, after these two items have been assessed by the parent, we go to Part B. In Part B, the developmental specialist checks the child's reaction by performing the second question himself. For example, in room 12, Aynur khanum tried to show Mohammad a colored ball with sound from the other side of the room. Because these children are distracted, they will react it a bit later.

Draw the child's attention, then point to an interesting object in the other corner of the room and say, "Look! There is a ... (name of the toy) ". Look at the child's face. Does the child look to the other side of the room to see what you are pointing to? Yes / No.

It should be noted that the conditions for each section of the test are also noted. Therefore, the mentioned part is given in addition to the 2 nd question.

Place the defined object in a corner of the room so that it is at least 1.5 meters away from you and the child and there is no other object around. To test this ability you need to repeat at least 5 times.

Part B focuses on children's developmental indicators. 54 children out of 214 children in the study responded quickly to the development specialist when testing such tasks. For example, when a 
psychologist implemented the above mentioned task, children who six months ago could not even react to their names, looked across the room to look for a toy. Unfortunately, many children with autism hadn't not been able to respond to calls and gestures no matter how many times they tried. Since nothing is sometimes of interest to children with deep autism, such tasks with these children once again reflect how serious the problem is.

If the child looks at the object you are pointing to in at least two of the 5 tests, yes, it is successful. Attract the child's attention, give him a toy car / doll and ask : "Will you drive the car / put the doll to bed?". Does the child perform symbolic actions such as driving a car / puting the doll to bed? Yes / No

In Part B, question 3 really reflects the development of the child. From an early age, children acquire the ability to drive a car or put the doll to bed. They are considered to be one of the easily learned imitations by the children. If children do not acquire this ability after 18 months, it means that the child has autistic symptoms. The developmental specialist should also take into account the child's shyness. This section allows you to diagnose important stages in a child's development.

In the past, children with autism turned the wheels of cars instead of driving, and instead of playing with their dolls they took out their arms and looked at them for hours. Some parents complained about their children noting that they still indifferent to toys and hane no interest in anything. These are mainly children with severe autism.

Ask the child "Where is the light?" Or say, "Show me the light." Does the child point the light with his index finger? Yes / No

This is the last item. In this case, the development specialist still tries to address questions to the child. This article serves to re-examine question A7 in PART A. So, here we ask questions to see if the child has the ability of pointing or not, as well. Thus, after all the questions are answered, parents are looking forward to the final opinion. This is the most interesting stage of the test.

Table 3.

Results of CHAT test

\begin{tabular}{llll}
\hline & Division over groups & With number & With \\
\hline 1. & Children with Autism & 115 & 53,7 \\
2. & Children with autistic & 45 & 21 \\
& symptoms & & \\
3. & Children with no symptoms & 51 & 25,3 \\
4. & Tested children & 214 & 100 \\
\hline
\end{tabular}

After explaining each section, I would like to point out that the questions I mentioned above are critical questions. If the answer to these questions is "no", it is likely that the child has autism syndrome. The test results are given in table Table 3.

The table helps us to show the results more clearly. The number of children with autism who entered the center was small because they had already completed the rehabilitation process and were integrated into society as the problem was not so deep. Some children with autism have completely cured as a result of intervention at an early age. 
During the implementation of the test, we saw that some parents wrote their opinions on the test paper. About 160 children with active autism syndrome were found and registered among the children participating in the test (Figure 1).

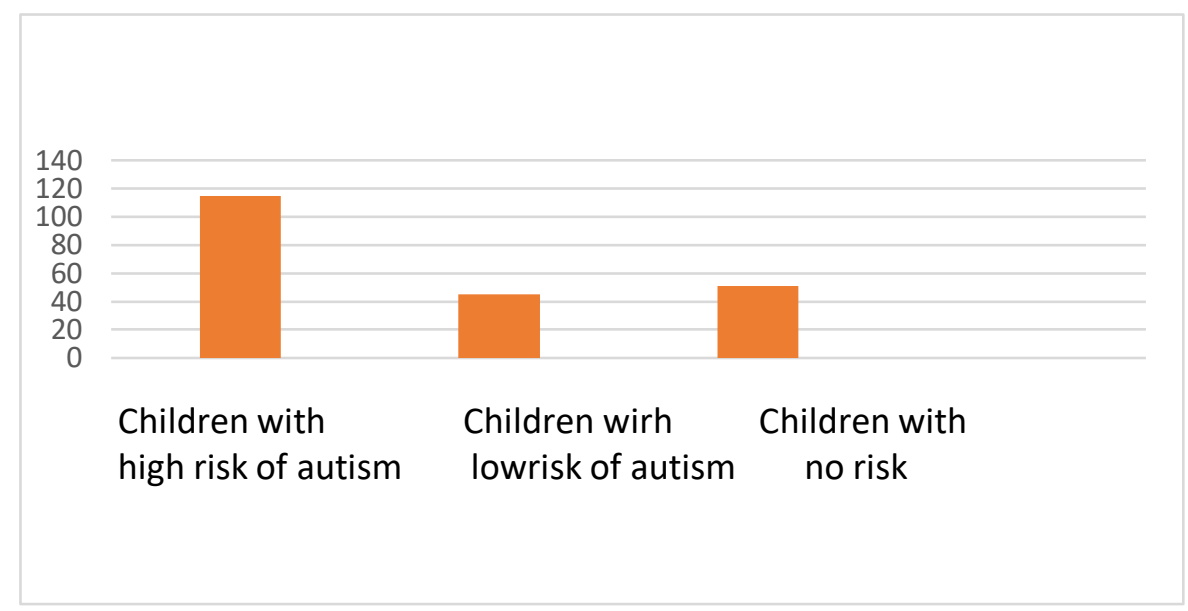

Figure 1. Distribution of tested children according to the risk of autism.

Example: A child named Matin, who entered the center for 1 year and 3 months, did not respond to his name from the first day of his arrival, and was distinguished by his indifference to children. The mother always complained about the child's indifference. But the child lost the active symptoms of autism after training. Their parents are very happy with the results.

We are considered to have reached the main goal while taking the CHAT test. Our main goal in the study was to determine the percentage of children with autism in the center. By the time they entered the center,most of them had already been diagnosed by a neurologist and psychiatrist. Parents of many children diagnosed with autism on the CHAT test said they were familiar with the test abroad (figure 2).

-screening and diagnostics;

- differential diagnostics;

- depth study of the child, and finally

- Development of individual correction program. 


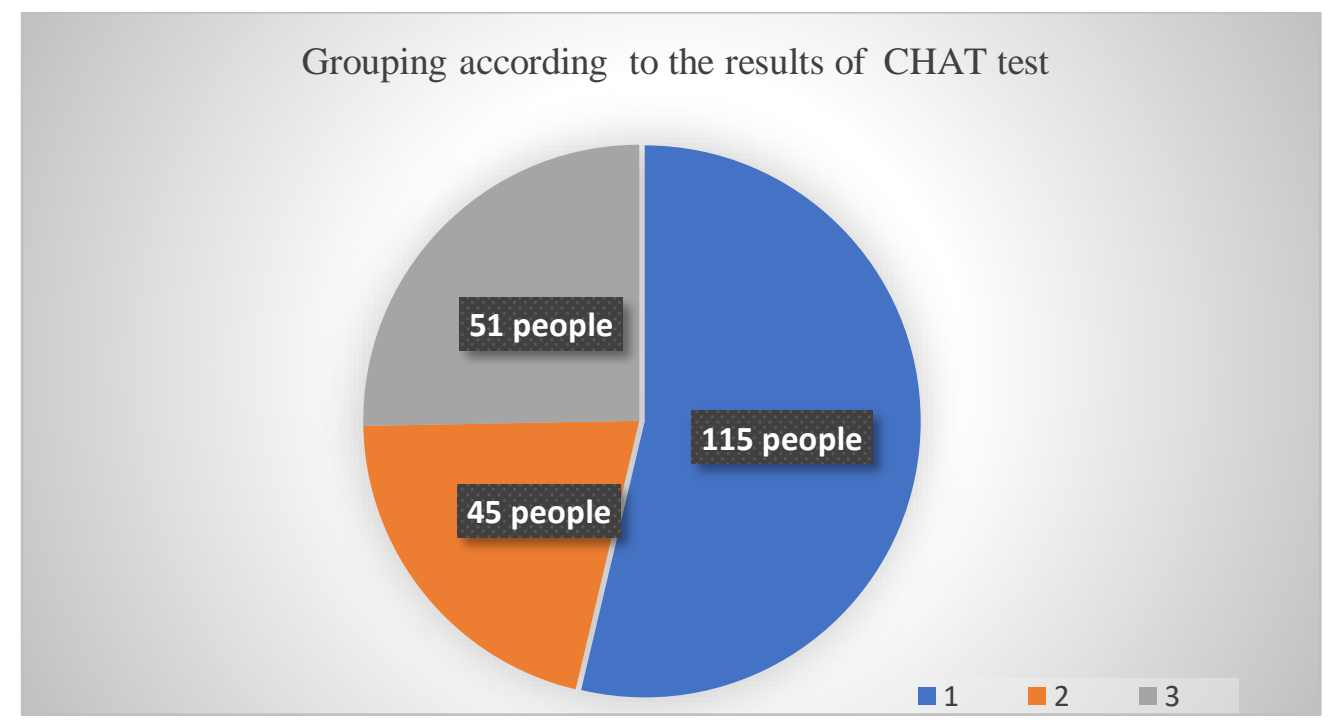

Figure 2. Distribution of CHAT test participants in terms of attitudes towards autism

Each stage has its own specific tasks and each stage has its own problem area. As you see, the first stage is called "screening".

At this stage, the presence of digression in the psychophysiological development of the child is revealed, but in this case the exact classification of the nature and depth of this digression is not given (it is the task of the following two stages).

The main tasks of screening-diagnostics are the timely detection of children with various deviations and disorders in the mental development of the population (including public educational institutions), the approximate definition of the range of psychological and pedagogical problems of the child.

Various tests and technologies are used to identify existing disorders of psychomotor development in young children. Screening is considered one of the effective technologies in this area.

Screening technologies are used in the early stages of early detection (psychodiagnostics) of impaired (or suspected impaired) development in children (this process is called "screeningdiagnostics").

Although this method is more responsive to modern requirements for the detection of children with developmental disorders, it is rarely used.

Typically, in the process of comprehensively assessing the level of psychomotor (psychomotor) development, two different levels of mental and motor development are considered. In this case, the levels of speech development and social adaptation in the mental development of the child are differentiated. The first is important to take into account sensory and motor speech, and the second combines sensory and emotional development.

In turn, at the level of motor development, there are sub-levels of general motor activity (a desirable point for static and motor functions) and manual dexterity. 
During the screening-diagnostics, the assessment of the manifestation levels of habits and skills characterizing psychomotor development is carried out. In this case, the determination of their following levels is planned:

- the level of harmony (in this case, the changes that have occurred in the development of all the above-mentioned sub-levels (whether positive or negative) do not exceed one age interval;

- slight disharmony (these changes are two age intervals);

- acute disharmony (developmental changes at all sub-levels are more than three age intervals).

If, according to the results of screening - diagnostics, the mental development of children of a certain age group corresponds to the psychomotor indicators of the passport age to which they belong, the changes (both positive and negative) do not exceed an age range, then development is considered appropriate to pasport age (harmony level).

The results of the Denver-II test are interpreted more precisely as follows. If, within the specific age group under examination, the indicators of psychomotor development of its specific members differ by more than two age intervals from the indicators corresponding to the passport age of this group, then:

- If the indicators of psychomotor development are higher than the indicators corresponding to the passport age of this group, preventive development is established;

- Conversely, if psychomotor indicators lag behind the relevant passport age, it is considered a developmental retardation.

Finally, if the diagnostic indicators lag behind the corresponding passport age indicators by three or more age intervals, then retardation in psychomotor development is emphasized.

The Denver II test was conducted at the Center for Modern Psychology (Narimanov, Baku) with 160 children ( 2 to 6 years old) brought to the center for having some problems in their development. The age distribution of the children is presented in Figure 3.

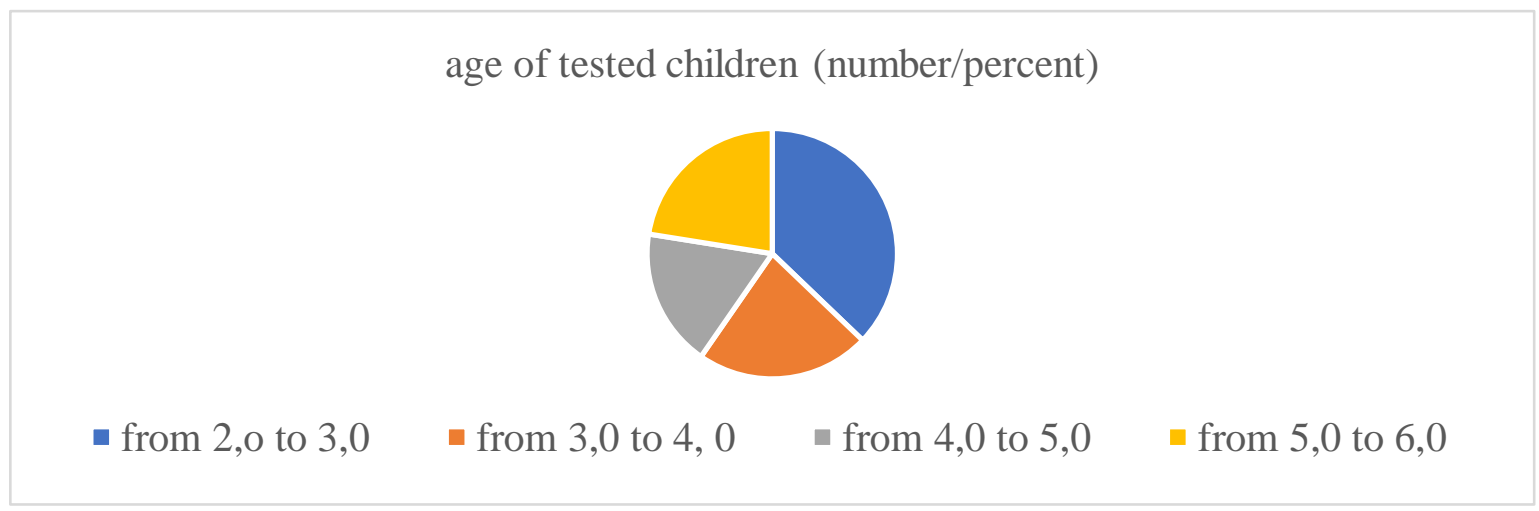

Figure 3. Age of children participated in the Denver test II

According to the results of the Denver II screening test, 160 children who sent to the center as a result of the possibility of mental retardation were tested, and it became clear that 14 $(8.75 \%)$ out of 160 children had no retardation in psychomotor and social skills (Figure 4). 


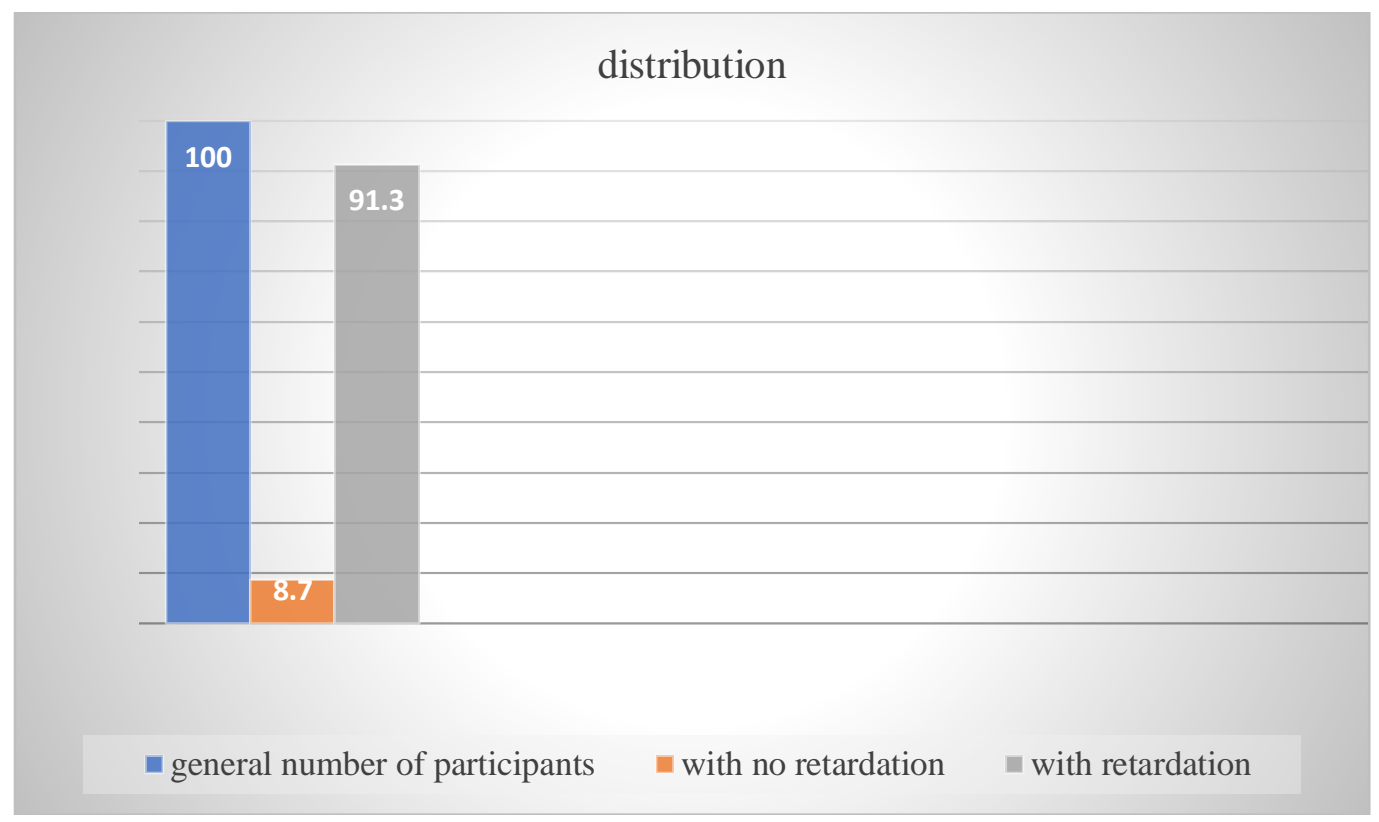

Figure 4. Distribution of tested children according to develeopment level

In the remaining children (from 2 to 6 years) $-91.3 \%$ of the total number (146 people) in various areas of psychomotor development (speech, small motor skills, large motor skills and the development of personal and social skills) retardation was observed.

\section{Table 4.}

Division by delays in different areas of development.

\begin{tabular}{llll}
\hline S. s. & Area of stunted development & \multicolumn{2}{c}{ number } \\
\cline { 3 - 4 } & & With number & With \% \\
\hline 1. & Social-adaptive functions & 125 & 78 \\
2. & Speech and thinking functions & 132 & 82,5 \\
3. & Small motor coordination & 138 & 86,25 \\
4. & General and high motor skills & 141 & 88,2 \\
\hline
\end{tabular}

Depending on the which mental area (social-adaptive functions, speech and thinking functions, small motor coordination and general large motor skills) they have impaired, these children are divided as follows (Table 4).

On the other hand, the distribution according to the number of areas where developmental disorders were detected gave the following result (Figure 5). 


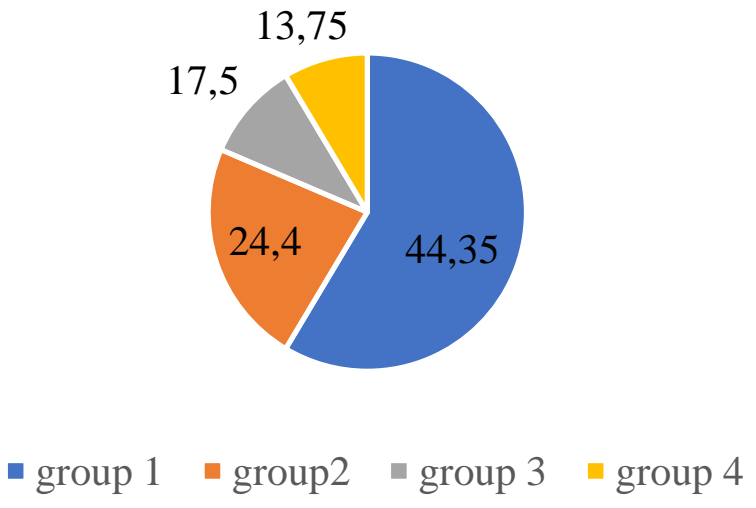

Group 1: this group includes children with developmental disorders - 17.5\% (28 people);

Group 2: developmental disorders are observed in two areas - $13.75 \%$ (22 people);

Group 3: children with developmental disorders in three of the diagnosed areas $-24.4 \%$ (39 people)

Group 4: this group included children with developmental disorders in all areas examined - 44.7\% (71 people).

Figure 5. Distribution by groups, depending on the number of areas of developmental disorders

Table 5.

Distribution of subjects according to the level of psychomotor development

\begin{tabular}{|c|c|c|c|c|}
\hline q.1 & $\begin{array}{l}\text { psychomotor } \\
\text { level }\end{array}$ & Carachteristics of results & number & $\begin{array}{l}\text { with } \\
\%\end{array}$ \\
\hline 1. & $\begin{array}{ll}\text { "Preventive" } & \\
\text { level in } \\
\text { psychomotor } \\
\text { development }\end{array}$ & $\begin{array}{l}\text { 1.1. Two or more "preventive" responses were } \\
\text { obtained for any two or more of the four sub- } \\
\text { levels. } \\
\text { 1.2. There are } 2 \text { "preventive" answers for one } \\
\text { of the four sub-levels and } 1 \text { "preventive" } \\
\text { answer for the other (provided that there is } \\
\text { no "negative" answer for this sub-level). }\end{array}$ & 4 & 2,5 \\
\hline 2. & $\begin{array}{l}\text { Retardation in } \\
\text { psychomotor } \\
\text { development }\end{array}$ & $\begin{array}{l}\text { Two or more "negative" answers were } \\
\text { obtained for any two or more of the four } \\
\text { sub-levels. } \\
\text { 2.1. There are } 2 \text { "negative" answers for one of } \\
\text { the four sub-levels and } 1 \text { "negative" answer for } \\
\text { the other (provided that there is no "preventive" } \\
\text { answer for this sub-level. }\end{array}$ & 132 & 82,5 \\
\hline 3. & $\begin{array}{l}\text { Mild or probable } \\
\text { retardation in } \\
\text { psychomotor } \\
\text { development }\end{array}$ & $\begin{array}{l}\text { 3.1. } 2 \text { or more "negative" answers for one of the } \\
\text { four sub-levels. } \\
\text { 3.2. There is } 1 \text { "negative" answer for any of the } \\
\text { four sub-levels, and there is no "predictive" } \\
\text { answer for this sub-level. }\end{array}$ & 10 & 6,25 \\
\hline 4. & $\begin{array}{l}\text { Psychomotor } \\
\text { development is } \\
\text { normal }\end{array}$ & $\begin{array}{l}\text { The test results do not match any of the } \\
\text { previous categories. }\end{array}$ & & \\
\hline \multicolumn{3}{|c|}{ General number of test objects } & 160 & 100 \\
\hline
\end{tabular}


Finally, according to the test results, the children in the experiment were distributed according to their level of psychomotor development as follows (Figure 3.). Levels of psychomotor development and their individual characteristics (as well as expressed in numbers and percentages) are presented in Table 5.

Analysis of these results allows us to clearly compare the current situation. Unfortunately, the vast majority of children we diagnosed psychologically had symptoms of autism.

The disadvantage of autism is that the disease manifests itself only after age two, mainly when children begin to develop behavior and eye contact. It can be assumed that the physical connection in autism syndrome is incorrect. But it affects the quality of life. That is, a person with autism is unable to target himself in a social environment and has a problem with it. It is known that most families face problems in this area. Autistic children have some difficulties in behaving and communicating in a social environment. This is not unequivocally welcomed in society. Crying or laughing for no reason and suddenly shouting are among their typical behaviors.

Initially, these symptoms can be observed in newborn children after birth, the main symptoms appear in two to three months. These children do not react to calls and can not make eye contact. If parents suspect these symptoms, they should consult a specialist. The neurologist should be consulted first, and after the diagnosis, the doctor will direct the child with autism to appropriate rehabilitation.

The importance of early diagnosis should be emphasized. We can not deny its positive effect on the result. The problem is mainly manifested by a lack of speech and eye contact, but this is the visible side. In a normal child, at the age of one year and two months, we should hear the words addressed. But if we no longer observe at least syllables in a 1-year-old or 2-month-old child, then there is a problem. Not having an eye contact makes difference between other speech defects.

First of all, it should be determined that the hearing is normal. An autistic child does not turn around when called, but reacts to the rustle of any candy wrapper or the sound of a favorite advertisement. They can react excessively to certain sounds. For example, they may react to the sound of a car by standing, shouting, or holding their ears. This is because they are extremely sensitive. We can focus where we need to, but in children with autism, speech is a visible side.

Most children with autism don't have speech, and in some of them get it after a certain period of time. These children often do not understand questions, jokes, and commands, even if they begin to say simple words. That is why it is so difficult for them to communicate with the people around them. Even when children begin to speak, we can observe some problems such as stress, the correct pronunciation of words in their speech.

These children have limited interests and behaviors, such as picking things up in the mouth, reacting harshly to change, walking on tiptoes, clapping, tapping fingers, playing with a particular part of the body or any part of clothing, and being prone to mechanical movements. (turn the light on and off). Children with autism can watch a car turn for hours. In this regard, the movie The Miracle of Love is a good example of a child turning around for a long time. For this type of child, engaging in monotonous stereotypical movements for hours is one of the main features. These children can play with objects emotionally. For example, when they come across something new, they bite it and smell it. 
Table 6.

Psychological characteristics of children with autism in preschool age according to the results of diagnosis

\begin{tabular}{|c|c|c|}
\hline & $\begin{array}{l}\text { Emosion } \\
\text { al area }\end{array}$ & $\begin{array}{l}\text { - similarity and weakness of emotions; } \\
\text { - Weakness or distortion of emotional reactions (acute reaction to events that } \\
\text { are common for other children and, conversely, failure to react to } \\
\text { emotionally significant events); } \\
\text { - the tendency to be afraid of everything new, to preserve the immutability } \\
\text { of the things and people around them; } \\
\text { - Excessive number of inadequate fears: fear of going out, fear of using } \\
\text { transport, fear of being alone in the apartment, etc. }\end{array}$ \\
\hline 2. & $\begin{array}{l}\text { Social } \\
\text { behavior, } \\
\text { communi } \\
\text { cation }\end{array}$ & $\begin{array}{l}\text { tendency to "rituals", stereotypical behavior and actions; } \\
\text { - peculiar visual behavior in communication: the child does not look into the } \\
\text { eyes of the partner, in most cases looks away; } \\
\text { - in most cases does not react to the appeal to him, does not "see" those } \\
\text { around him. }\end{array}$ \\
\hline 3. & $\begin{array}{l}\text { Cognitiv } \\
\text { e area }\end{array}$ & $\begin{array}{l}\text { disorder of the completeness of perception: perceives objects on the basis of } \\
\text { individual features; } \\
\text { - visual perception is fragmentary: better perceives distant objects. }\end{array}$ \\
\hline & $\begin{array}{l}\text { Motor } \\
\text { area }\end{array}$ & $\begin{array}{l}\text { - motor incompetence, awkwardness in movements; } \\
\text { - lack of coordination in arbitary actions; } \\
\text { - weaknes and repetition of facial expressions; } \\
\text { - stereotypical repetition of actions. }\end{array}$ \\
\hline
\end{tabular}

5. Speech does not try to use his speech to communicate with the people around him; - speaks about himself as a third person, avoids any direct appeals;

- seldom asks a question to an adult, gives unambiguous answers or does not answer questions;

- has a selective attitude to words: some words arouse fear, dissatisfaction, and repeats others for many times;

- sometimes mutism (lack of speech) is observed

6. Commun The child feels comfortable when he is alone;

ication - can not interact with other children;

- The relationship with the mother can be expressed in different ways: from not reacting to the presence or absence of the mother to the expression of aggression, to negativity; the opposite may happen as well: a symbiotic relationship with the mother, anxiety about her absence, but no emotional response when her mother is with her.

7. Games - games, in most cases, stereotypical manipulations with non-toys and objects that he can not use purposefully (string, glass, etc.);

- plays alone, does not react to his partner participating in the game;

- can sit for hours, arranging objects and toys in a certain order, trying to separate him from the game creates emotional discomfort and affective reactions;

- There are unusual interests: the child can "have fun" with traffic signs, phone numbers, various symbols, words in foreign languages.

As mentioned above, they have strong habits, such as the same type of clothing, the same type of nutrition system, the same shape of the house, and so on. We have heard complaints from parents of children with autism that in many cases, when a child enters the house, he pushes furniture and starts knocking them to the ground. A mother who asks a psychologist for her 
reasons is often told, "You probably made changes in the house that day." Naturally, a child with autism begins to react aggressively to changes at home.

I would like to give information about a child named X. (2.4 years old) who has been in therapy for 6 months. At the first meeting, we found out how caring and open-minded the family is. The results of the child's tests were as follows: CHAT test - Autism elements are observed. According to the DEVER-II test, the result was abnormal. Within 6 months, the results began to differ sharply. The child began to socialize. Academic results have improved. Attention developed. Compared to other children in the center (with the same diagnosis), the results of this child were even faster.

\section{Discusión}

Our research has shown that for centuries, people with autism have been viewed in society as a kind of disabled person. Disability is a condition in which a person is unable to meet his or her needs fully or partially independently due to a lack of physical and mental abilities.

We can summarize the results of our research as follows:

- In the mental development of preschool children with autism, high, medium, low and zero levels were recorded in accordance with both the type of autism and the individual characteristics of the child and the conditions of social development in the family. As a result of these developmental and correctional efforts, self-awareness is higher in children with autism than in those with high functional and Asperger's syndrome. The main structural components of personality begin to develop, they differentiate themselves and the people around them, use personal pronouns freely in speech, show interest in communication, and perform mental operations.

- Psychological correction of children with ASD syndrome becomes more effective if this process is based on the characteristics of the cognitive and affective aspects of the child's self-consciousness, the development of his communication skills, game and movementgraphic activities and if the formation of autistic child's voluntary behavior and intellectual field is formed harmoniously.

Correctional work in this area is possible with the provision of the following differentiated principles: understanding of the general patterns of mental development of preschool children with normal and abnormally developed levels; individual approach to children; taking into account the age-related psychological characteristics; creation of a positive emotional background in the relations between children and adults; involvement of all family members in working with a child with autism.

Effective psycho-pedagogical correction of the self-consciousness of a preschool child with ASP syndrome requires special conditions. The most important of these conditions are as follows: implementation of comprehensive medical-psychological-pedagogical support for preschool children with ASD syndrome; work with the family of an autistic child, including the education and counseling of parents on the upbringing and development of the child, the involvement of family members in individual and group activities, etc; organization of step-by-step psychocorrectional work on an individual program in order to develop the child's affective area as a system of affective organization of behavior and perception in accordance with the nearest defined development zone; precise organization of classes, formation of a comfortable development environment; selection and application of adequate methods of self-correction. 


\section{Referencias}

Aliyeva K.M. (2015). Autism and Training. Baku, 98 p.

American Psychiatric Association (2000). Pervasive developmentel disorders. Washington: DC American Psychiatric Association, $70 \mathrm{p}$.

Appe F. (2006). Introduction to the psychological theory of autism. M: Terevinf, $216 \mathrm{p}$

Aydemir S.E. (2015). Examination of the Marriage harmony, Understanding Strategies and

Perceptions of Social Support of Parents of Autistic Children. Izmir: Dokuz Eylul University Institute of Educational Sciences, $72 \mathrm{p}$.

Blair E. (1920). Psychiatry Guide: Per. with him. SPb: 538 p.

Frith U. (1997). Autism, Explaining the Enigma, Blackwell. London. Dissanayake, C. Crossley, S.A., 92 p.

Kınac1 A.(2013). There is a solution to autism. Istanbul: Hayykitap, $271 \mathrm{p}$.

Kagan V.E. (1981). Autism in children. L .: Medicine, 206 p.

Resources on Autism (2006). Baku: Ministry of Health, 34 p.

Wing L. (1981). Asperger's syndrome: aclinical account. London: Psychological Medicine, 11, p. 115-129. 